\title{
OPTIMUM WORKFORCE-SIZE MODEL USING DYNAMIC PROGRAMMING APPROACH
}

\section{S. A. OGUMEYO}

(Received 14, January 2010; Revision Accepted 4, May 2010)

\begin{abstract}
This paper presents an optimum workforce-size model which determines the minimum number of excess workers (overstaffing) as well as the minimum total recruitment cost during a specified planning horizon. The model is an extension of other existing dynamic programming models for manpower planning in the sense that it strikes a balance between overstaffing and understaffing at each stage of the computations. The model also considers a manpower planning system in which the employment level has upper and lower bounds. The employment level varies from one period to another while the cost incurred in each period depends only on recruitment size and the overstaffing cost from an earlier stage. A mathematical problem is formulated and solved to illustrate the model numerically.
\end{abstract}

KEYWORDS: Workforce-size, dynamic programming, Optimum, Overstaffing and Understaffing.

\section{INTRODUCTION}

Dynamic programming is a mathematical technique which deals with the optimization of multistage decision problems. According to Gupta (2005), the originator of dynamic programming was Richard Bellman in 1952. Over the years dynamic programming has been applied to solve many real life problems such as resource allocation, capital budgeting, replacement of worn-out equipment and so on, Taha (2002), Mehlmann (1980), opined that in the last two decades a body of literature on dynamic programming has been developed to focus on manpower planning. Mehlmann (1980) developed optimal recruitment and transition strategies for manpower system using dynamic programming technique. Mehlmann (1980) remarked that dynamic programming models for solving manpower planning problem is centred on the importance of correct manning of each grade under preferred recruitment and transition patterns.

Taha (2002) developed a manpower planning model which was based on the determination of when employees should be hired or fired. Taha (2002) further stated that hiring and firing of employees should be exercised from time to time in manpower planning system to checkmate incidents of understaffing and overstaffing. Sterman (2000), developed a model which was centered on civil and military manpower planning using Markov chains to determine optimal workforce-size. Raghavendra (1991) and Ekoko (2006), applied Markov chain models to manpower planning with respect to promotion and recruitment factors.

Zanakis and Maret (1981) formulated a Markovian goal programming model with a pre-emptive priorities and provided a more flexible and realistic tool for manpower planning problem. Price and Piskor (1972) formulated a goal programming model of manpower planning system for officers of the Canadian armed forces to reduce the weighted sum of money spent on their military. Rao (1990) developed a dynamic programming model to determine optimal manpower recruitment policies using dynamic programming technique by forward recursive approach.

While Ogumeyo and Ekoko (2008) developed a manpower planning model to determine optimal recruitment policies using a dynamic programming technique involving a backward recursive approach. Hillier and Lieberman (2001) argued that the workforce size of every business organization is subject to seasonal fluctuation due to the fact that certain machine operators are difficult to train and at times not readily available for hire when they are needed. Hence, overstaffing is inevitable.

The major problem in manpower planning is how to strike a balance between having too many staff (overstaffing) and not having enough staff (understaffing) in a business organization. These two extremes (overstaffing and understaffing) both have negative effects on any business organization. While overstaffing leads to economic law of diminishing return, understaffing results in low productivity and decrease in revenue generation. Many research work in literature on manpower planning deals with minimization of manpower cost without addressing the problem of narrowing the gap between understaffing and overstaffing.

S. A. Ogumeyo, Department Of Mathematics, Delta State, College Of Physical Education, Mosogar, P.M.B 4088, Sapele, Delta State. 
The model presented in this paper establishes a recruitment schedule for a category of workers during the next T time periods, in which understaffing is not allowed. The schedule seeks to minimize the total recruitment and overstaffing cost subject to the restriction that it meets the entire demand requirement on time.

\section{FORMULATION OF THE OPTIMUM WORKFORCE-SIZE MODEL}

In formulating the optimum workforce-size model, the following assumptions are being considered as necessary conditions.

a. Each period required workforce-size must be entirely satisfied on time in order to avert understaffing.

b. The required workforce-size varies from period to period due to seasonal fluctuation

c. The initial workforce-size is known and fixed.

d. The overstaffing level must be zero at the end of period $\mathrm{T}$, (that is, $i_{T}=0$ )

\section{Mathematical Notations}

The following mathematical notations are used in the formulation of the model

$x_{t}=$ workforce-size recruited in period $\mathrm{t}$

$i_{t} \quad=\quad$ Overstaffing level at the end of period $\mathrm{t}$.

$i_{t-1}=$ overstaffing level from an earlier period $\mathrm{t}$.

$i_{t-1}+x_{t}=\quad$ Total number of staff available to meet future manpower demand in period $\mathrm{t}$.

$d_{t}=\quad$ fixed required workforce-size in period $\mathrm{t}$.

$C_{t}(x, i)=$ Cost of recruiting $x=$ workforce-size and having i quantity of overstaffing employees in period $\mathrm{t}$.

$x_{t}(i)=$ a recruitment level yielding $f_{t}(i)$

$f_{t}(i)=\quad$ minimum policy cost when the overstaffing quantity is

at level $i$ with $t$ more periods to go.

From the above assumption stated in (d), management desires a recruitment policy in which the level of overstaffing is zero at the end of period

$$
T, i_{T}=0 \text {. }
$$

Each period workforce-size requirement must be entirely satisfied on time in order to avert understaffing, that is

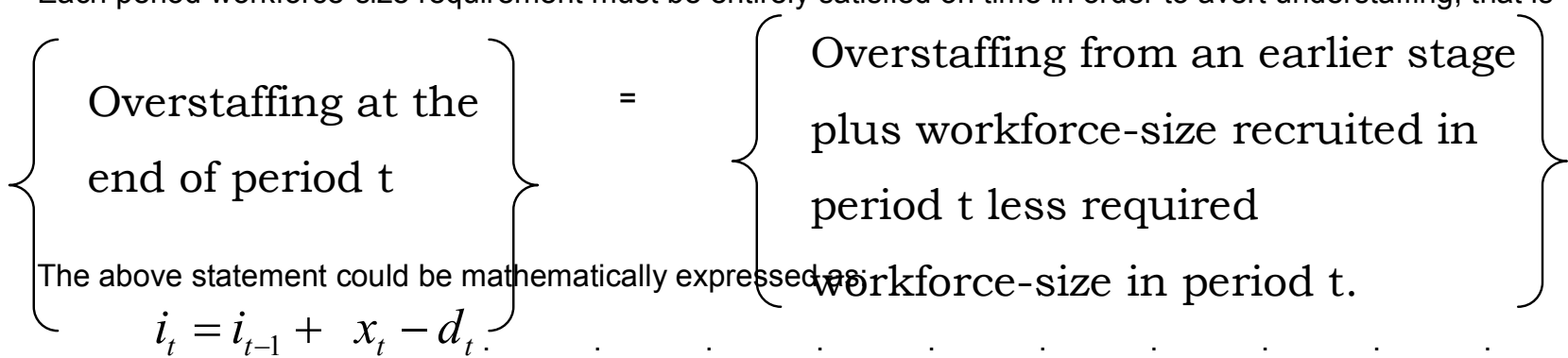

Rearranging the terms in equation (2) we have

$$
i_{t-1}+x_{t}-i_{t}=d_{t} \text {. }
$$

$$
\text { for } t=0,1,2,3 \ldots T \text {. }
$$

where $i_{o}$ is a specified level of initial overstaffing at the beginning of the planning horizon.

Since overstaffing at the end of the horizon is zero by the assumption of the model,

$$
\begin{aligned}
& f_{t}(i)=x_{t}(i) \text { implies that } \\
& f_{o}(0)=0 \text {, for } t=0
\end{aligned}
$$

This model required some constraints to be impose on the policy variables $x_{t}, d_{t}$ and $i_{t}$. This constraints are:

i. We restrict recruitment to be integer valued, that is, no part-time workers are recruited, hence $x_{t}=0,1,2,3 \ldots$ for each period t. also $d_{t}=d_{1}, d_{2} \ldots, d_{T}$, for $t=0,1,2,3 \ldots$

ii. Each period's overstaffing from an earlier stage and the recruitment workforce-size at the present stage must always be large enough to make overstaffing quantity at the end of period $t$ nonnegative value. That is, $i_{t}=0,1,2, \ldots$ at each period for $t=1,2,3 \ldots T$. 
Remark

The relationship in equation (3) ensures that overstaffing from an earlier period plus recruitment in period $t$ is sufficient to meet manpower requirement in period $t$.

When $t=1$, the overstaffing quantity $i$ from an earlier stage can be any integer amount between the limits of 0 and $d_{1}$; but regardless of the specific level, the recruitment size must be $d_{1}-i$ so that all of the final period's manpower requirement is met. It follows then that

$f_{1}(i)=C_{1}\left(d_{1}-i, 0\right)$, for $i=0,1,, d_{1}$.

Next, we consider $t=2$ From the mathematical notation in this model, the overstaffing quantity is designated by $i$ and the recruitment level by $x$, hence the associated cost is

$$
C_{2}\left(x, i+x-d_{2}\right)+f_{1}\left(i+x-d_{2}\right) \text {. }
$$

where the quantity $i+x-d_{2}$ is simply the overstaffing quantity at the end of the period. The value for $\mathrm{i}$ can be any integer amount between $o$ and $d_{1}+d_{2}$; if it exceeds $d_{1}+d_{2}$, then equation (1) is not satisfied, since end-of-horizon overstaffing will be positive. Given $\mathrm{i}$, the integer value of $x$ must be at least as large as $d_{2}-i$, in order to meet the period's manpower requirement, but not larger than $d_{1}+d_{2}-i$ since overstaffing quantity must be $o$ at the end of the period. An optimal recruitment quantity $x$ is one that minimizes the above sum in (b). The value of $t=2$ can be computed thus:

$$
\mathrm{f}_{2}(\mathrm{i})=\operatorname{minimum}\left[C_{2}\left(x, i+x-d_{2}\right)+f_{1}\left(i+x-d_{2}\right)\right]
$$

where $i=0,1 \ldots, d_{1}+d_{2}$ and the minimization is over only nonnegative integer values $x$ in the range $\mathrm{d}_{2}-\mathrm{i} \leq \mathrm{x} \leq \mathrm{d}_{1}+\mathrm{d}_{2}-\mathrm{i}$

For $\mathrm{t}=3$, we have

$$
f_{3}(i)=\underset{X}{\operatorname{Minimum}}\left[C_{3}\left(x, i+x-d_{3}\right)+f_{2}\left(i+x-d_{3}\right)\right]
$$

With $x$ in the range $d_{3}-i \leq x \leq d_{1}+d_{2}+d_{3}-i$

The general recursion is written as

$$
f_{t}(i)=\underset{X}{\operatorname{Minimum}}\left[C_{t}\left(x, i+x-d_{t}\right)+f_{t-1}\left(i+x-d_{t}\right)\right]
$$

For $t=1,2, \ldots T$

Where $i=0,1 \ldots d_{1}+\ldots+d_{t}$ and the minimization is over only nonnegative integer values $x$ in the range $d_{t}-i \leq x \leq d_{1}+d_{2}+\ldots+d_{t-1}$

We observe that by letting overstaffing quantity $i$ be the state variable, the only independent decision variable in the recursion (6) is $\mathrm{x}$, since overstaffing at the end of the period is simply $\left(i+x-d_{t}\right)$. We also observe that since $f_{0}(0)$ and $f_{1}(i)$ are easily computed in (4) and (5), we can in turn calculate $f_{2}(0)$, $f_{2}(1) \ldots, f_{2}\left(d_{1}+d_{2}\right)$, then $f_{3}(0) \ldots, f_{3}\left(d_{1}+d_{2}+d_{3}\right)$, continuing for successively larger values of $\mathrm{t}$, eventually to $f_{T-1}(0), f_{T-1}(1) \ldots, f_{T-1}\left(d_{1}+d_{2} \ldots+d_{T-1}\right)$ and finally to $f_{T}\left(i_{0}\right)$.

To find an optimum recruitment schedule, we then check what recruitment level $x_{T}\left(i_{0}\right)$ yielded the value for $f_{T}\left(i_{0}\right)$; this is an optimal decision at the start of the horizon. At the next stage, overstaffing quantity from an earlier stage will be $i_{0}+x_{T}\left(i_{0}\right)-d_{T}$. Then find a recruitment level that yields the value for $f_{T-1}\left(i_{o}+x_{T}\left(i_{o}\right)-d_{T}\right)$ and so on.

\section{The Dynamic Programming Algorithm For The Model}

The dynamic programming algorithm for the optimal recruitment schedule can be summarized as follows:

Step 1: First Stage computation,

$$
\text { Compute } \quad\left\{\begin{array}{l}
x_{t}(i)=f_{t}(i) \\
f_{0}(0)=0, \text { for } t=0
\end{array}\right.
$$

Step 2 for $t=1$, compute $f_{1}(i)=C_{1}\left(d_{1}-i\right)$, for $i=0,1,2, \ldots d_{1}$ 
Step 3. for $t=2$, compute $f_{2}(i)=\min \left\{C_{2}\left(x, i+x-d_{2}\right)+f_{1}\left(i+x-d_{2}\right)\right\}$

Where $i=0,1,-d_{1}+d_{2}$ and $d_{2}-i \leq x \leq d_{1}+d_{2}-1$

Step 4 for $t=1,2 \ldots, T$, compute $f_{t}(i)=\min \left\{C_{t}\left(x, i+x-d_{t}\right)+f_{t-1}\left(i+x-d_{t}\right)\right\}$

Where $i=0,1,-d_{1}+\ldots d_{1}+\ldots+d_{t}$ and $d_{t-i} \leq x \leq d_{1}+d_{2}+\ldots+d_{t-1}$

\section{NUMERICAL ILLUSTRATION}

In an establishment, the minimum number of employees $d$ required at each stage of a particular project is 5 and the fixed recruitment cost $C\left(x_{t}\right)$ for recruiting $X$-employees in $t$ periods is said to be known. These known values are

$d_{t}=1,2 \ldots \ldots d_{T}=5$ and $C(o)=0, C(1)=23, C(2)=26 C(3)=29 C(4)=32 C(5)=35, C(6)=38$

Use the dynamic programming algorithm in section 2 above to determine the optimum recruitment schedule for a period of six months in order to minimize overstaffing cost through out the periods.

\section{Solution}

Since the maximum estimated number of employees at the end of the planned period is 6 , the establishment cannot recruit more than 6 employees and cannot retain more than 5 excess workers at the end of any period.

Hence $x_{t}=0,1,2, \ldots 6$ and $i_{t}=0,1,2 \ldots .5$ for all periods.

Using the step 1 of the algorithm for $\mathrm{t}=1$,

$$
\left.\begin{array}{l}
f_{1}(i)=C(5-i) \\
x_{1}(i)=5-i
\end{array}\right\} \text { for } i=0,1, \ldots \ldots .5
$$

To ensure that the manpower requirement is met and the number of excess workers at the end of the horizon is zero.

Thus, the value of $f_{1}(i)$ is given in the table 1 below

Table 1: Initial Recruitment Cost for $t=1$

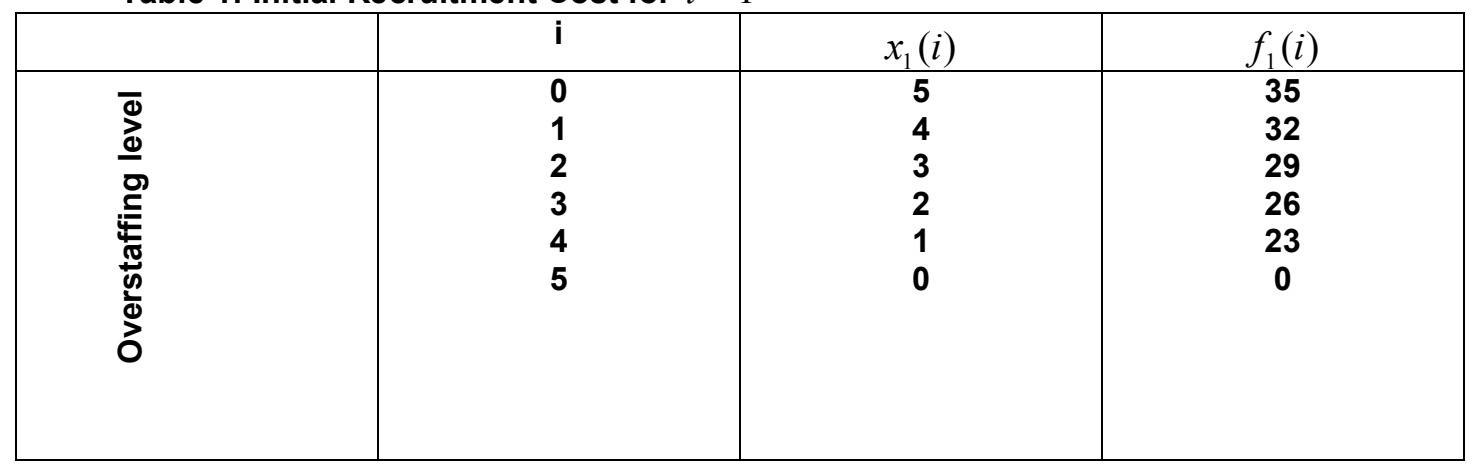

For $t=2$

Using the general recursion

$f_{2}(i)=C(x)+1(i+x-5)+f_{1}(i+x-5)$, the value of $f_{2}(i)$ is computed in Table 2. There are 6 rows and one for each feasible value of $i$. Several of the possibilities are blocked out. The first entry in each column $x$ is the value $C(x)$, the second entry is the cost of retaining excess workers $h=1$ times the number of excess workers. In the example, $i=5$ and $x=0$, hence overstaffing level is zero. And $o$ appears in the second term in sum for this case. When $i=3$ and $x=1$, then overstaffing level is 1 . Finally, the third term is the value of $f_{1}(i+x-3)$ calculated from an earlier stage. 
Table 2: $f_{2}(i)=C(x)+1(i+x-5)+f_{1}(i+x-5)$,

\begin{tabular}{|c|c|c|c|c|c|c|c|c|c|}
\hline$x$ & 0 & 1 & 2 & 3 & 4 & 5 & 6 & $x_{2}(i)$ & $f_{2}(i)$ \\
\hline 0 & & & & & & $35+0+35$ & $38+1+32$ & 5 & 70 \\
\hline 1 & & & & & $32+0+35$ & $35+1+32$ & $38+2+29$ & 4 & 67 \\
\hline 2 & & & & $29+0+35$ & $32+1+32$ & $35+2+29$ & $38+3+26$ & 3 & 64 \\
\hline 3 & & & $26+0+35$ & $29+1+32$ & $32+2+29$ & $35+3+26$ & $38+4+23$ & 2 & 61 \\
\hline 4 & & $23+0+35$ & $26+1+32$ & $29+2+29$ & $32+3+26$ & $35+4+23$ & & 1 & 58 \\
\hline 5 & $0+0+35$ & $23+1+35$ & $26+2+29$ & $29+3+29$ & $32+4+23$ & $35+5+0$ & & 0 & 35 \\
\hline
\end{tabular}

Thus, when $i=1$, with two periods left to go, the best recruitment level is 5 , which yields a cost of 26 for these two periods. Any other value for $x$ is more costly.

Similarly, the calculations for $f_{3}(i)$ are shown in table 3 below

Table 3: $f_{3}(i)=C(x)+1(i+x-5)+f_{2}(i+x-5)$,

\begin{tabular}{|c|c|c|c|c|c|c|c|c|c|}
\hline$x$ & 0 & 1 & 2 & 3 & 4 & 5 & 6 & $x_{3}(i)$ & $f_{3}(i)$ \\
\hline 0 & & & & & & $35+0+70$ & $38+1+67$ & 5 & 106 \\
\hline 1 & & & & & $32+0+70$ & $35+1+67$ & $38+2+64$ & 4 & 102 \\
\hline 2 & & & & $29+0+70$ & $32+1+67$ & $35+2+64$ & $38+3+61$ & 3 & 99 \\
\hline 3 & & & $26+0+70$ & $29+1+67$ & $32+2+64$ & $32+3+61$ & $32+4+58$ & 2 & 96 \\
\hline 4 & & $23+0+70$ & $26+1+67$ & $29+2+64$ & $32+3+61$ & $35+4+58$ & $38+5+55$ & 1 & 93 \\
\hline 5 & $0+0+70$ & $23+1+67$ & $26+2+64$ & $29+3+61$ & $32+4+58$ & $35+5+55$ & & 0 & 70 \\
\hline
\end{tabular}

Here $C(x)+1(i+x-5)$ is the first term and $f_{2}(i+x-5)$ is the second.

Following the same procedure, the remaining values of $f_{t}(i)$, for $t=4,5,6$ are summarized in table 4 .

Table 4: SUMMARY OF COMPUTATION FOR $t=1,2$

.6

\begin{tabular}{|c|c|c|c|c|c|c|c|c|c|c|c|c|}
\hline & \multicolumn{2}{|c|}{$t=1$} & \multicolumn{2}{c|}{$t=2$} & \multicolumn{2}{c|}{$t=3$} & \multicolumn{2}{c|}{$t=4$} & \multicolumn{2}{c|}{$t=5$} & \multicolumn{3}{c|}{$t=6$} \\
\hline $\boldsymbol{i}$ & $x_{1}(i)$ & $f_{1}(i)$ & $x_{2}(i)$ & $f_{2}(i)$ & $x_{3}(i)$ & $f_{3}(i)$ & $x_{4}(i)$ & $f_{4}(i)$ & $x_{5}(i)$ & $f_{5}(i)$ & $x_{6}(i)$ & $f_{6}(i)$ \\
\hline $\mathbf{0}$ & $\mathbf{5}$ & $\mathbf{3 5}$ & $\mathbf{5}$ & $\mathbf{7 0}$ & $\mathbf{5}$ & $\mathbf{1 0 6}$ & $\mathbf{5 , 6}$ & $\mathbf{1 4 1}$ & $\mathbf{5}$ & $\mathbf{1 7 6}$ & $\mathbf{5}$ & $\mathbf{2 1 1}$ \\
\hline $\mathbf{1}$ & $\mathbf{4}$ & $\mathbf{3 2}$ & $\mathbf{4}$ & $\mathbf{6 7}$ & $\mathbf{4}$ & $\mathbf{1 0 2}$ & $\mathbf{4}$ & $\mathbf{1 3 8}$ & $\mathbf{4}$ & $\mathbf{1 7 3}$ & $\mathbf{4}$ & $\mathbf{2 0 8}$ \\
\hline $\mathbf{2}$ & $\mathbf{3}$ & $\mathbf{2 9}$ & $\mathbf{3}$ & $\mathbf{6 4}$ & $\mathbf{3}$ & $\mathbf{9 9}$ & $\mathbf{3 , 4}$ & $\mathbf{1 3 5}$ & $\mathbf{3}$ & $\mathbf{1 7 0}$ & $\mathbf{3}$ & $\mathbf{2 0 5}$ \\
\hline $\mathbf{3}$ & $\mathbf{2}$ & $\mathbf{2 6}$ & $\mathbf{2}$ & $\mathbf{6 1}$ & $\mathbf{2}$ & $\mathbf{9 6}$ & $\mathbf{2 , 3}$ & $\mathbf{1 3 2}$ & $\mathbf{2}$ & $\mathbf{1 6 7}$ & $\mathbf{2}$ & $\mathbf{2 0 2}$ \\
\hline $\mathbf{4}$ & $\mathbf{1}$ & $\mathbf{2 3}$ & $\mathbf{1}$ & $\mathbf{5 8}$ & $\mathbf{1}$ & $\mathbf{9 3}$ & $\mathbf{1 , 2}$ & $\mathbf{1 2 9}$ & $\mathbf{1}$ & $\mathbf{1 6 4}$ & $\mathbf{1}$ & $\mathbf{1 9 9}$ \\
\hline $\mathbf{5}$ & $\mathbf{0}$ & $\mathbf{0}$ & $\mathbf{0}$ & $\mathbf{3 5}$ & $\mathbf{0}$ & $\mathbf{7 0}$ & $\mathbf{0}$ & $\mathbf{1 0 6}$ & $\mathbf{0}$ & $\mathbf{1 4 1}$ & $\mathbf{0}$ & $\mathbf{1 7 6}$ \\
\hline
\end{tabular}

\section{4. $\quad$ ANALYSIS OF RESULTS}

The tabulated numerical results needed to obtain optimal recruitment policy provide information about the model's parameters such as the length of the planning horizon and the level of overstaffing at the end of each period $t$.

Since each period in the model represents a month and that the first period is January. We want to know the optimal monthly figures change as the horizon T increases, and in particular, what happens to January recruitment. This leads to the next table, (Table 5) under the assumption that the overstaffing level at the beginning of January is $O$ based on Table 4.

Table 5: Recruitment Schedule Table

\begin{tabular}{|c|c|c|c|c|c|c|c|}
\hline $\begin{array}{c}\text { Planning } \\
\text { Horizon T }\end{array}$ & Jan & Feb & Mar & April & May & June & Cost \\
\hline 1 & 5 & & & & & & 35 \\
\hline 2 & 5 & 5 & & & & & 70 \\
\hline 3 & 4 & 6 & 0 & & & & 106 \\
\hline 4 & 5 & 5 & 0 & 0 & & & 141 \\
\hline 5 & 4 & 6 & 5 & 5 & 0 & & 176 \\
\hline 6 & 5 & 6 & 0 & 4 & 2 & 0 & 211 \\
\hline
\end{tabular}

Table 5 is constructed as follows.

When the planning horizon $t=1$, January recruitment $x_{1}(0)=5$ is found from Table 4 , first row under $t=1$. When the planning horizon $t=2$, January recruitment $x_{2}(0)=5$ is found from first row in Table 4 under $t=1$, since in 
January there are two periods remaining until the end of horizon. Then February's entering overstaffing is $O$, and so February recruitment is $x_{1}(0)=5$.

Skipping ahead to the case $t=6$, we first determine January recruitment $x_{6}(0)=5$ from the first row of Table 4 under $t=6$ since now in January there are six periods remaining until the end of the horizon. Consequently overstaffing entering February is $1=(i+x-d=0+5-4)$ and February recruitment is $x_{5}(i)=5$, which we find in Table 4 for $t=5$ with the new entering overstaffing $i=1$ (in February there are five periods remaining until the end of the horizon). This in turn means that overstaffing entering March will be $5=(i+x-d=5+5-5)$, so that March recruitment is $x_{4}(5)=0$ as shown in Table 4. The same line of reasoning establishes that April recruitment $x_{3}(0)=5$, since $t=3$ with entering overstaffing of $0=(i+x-d=5+0-5)$. With the April decision given, overstaffing in May is $0+5-4=1$, so that May recruitment is $x_{2}(1)=4,(t=2)$. Therefore, June recruitment $x_{1}(3)=2$ is optimal since entering overstaffing is $3+6-5=4$ with $t=1$. Thus the minimum total recruitment cost when $t=6$ is 211 which appeared as $f_{6}(0)$ in Table 4 .

\section{CONCLUSION}

The type of manpower planning problem treated in this paper is different from the common type of manpower planning problems that seeks total minimum recruitment cost without first of all determining the optimum recruitment schedules in each periods of planning horizon. From the illustrated numerical examples, we observe that the model presented in this paper indicate whether there should be overstaffing or not at each stage. Hence, the overstaffing level at the end of the planning horizon is zero and the minimum total recruitment cost is 211 which could be in 1000 s of Naira value.

\section{REFERENCES}

Ekoko, P. O., 2006. "Derivation of Transition Matrix for Staff Promotion Markov Model using PGF," Global Journal of Mathematical Sciences.

Gupta, P.K., 2005. “Operations Research”, New Delhi, S. Chand and Co. Ltd.

Hillier, F. S. and Lieberman, G.J., 2001. "An Introduction to Operations Research”, San Francisco: Holden Day.

Mehlmann, S. A., 1980. "An Approach to Optimal Recruitment and Transition Strategies for Manpower System Using Dynamic Programming" Journal of Operations Research Society, Vol 31, pp. 1009-1015.

Ogumeyo, S. A. and Ekoko P.O., 2008. "Dynamic Programming Algorithm For Optimum Manpower Recruitment Policy." Global Journal of Mathematical Sciences, Vol. 7, No 2 pp 107-114.

Price, W.L and Piskor, W.G., 1972. The Application of Goal Programming to Manpower Planning Journal of the Operations Research Society, Vol. 41, No 10, Pp. 221-231.

Rao, P.P., 1990. Determining Optimal Manpower Recruitment Policies, Journal of the Operations Research Society, Vol. 41. No 10, Pp. 983-988.

Raghavendra, B.G., 1991. A Bivariate Model for Markov Manpower Planning System, Journal of Operational Research Society Vol. 42 No 7, Pp 570-581.

Sterman, S.D., 2000. Business Dynamics: System Thinking and Modelling For a Complex World”, Boston: McGraw-Hill.

Taha, H.A., 2002. Introduction to Operations Research, New Delhi: Prentice -Hall of India.

Zanakis, S.H. and Maret, M.W., 1981. A Markovian Goal Programming Approach to Aggregate Manpower Planning, Journal of the Operations Research Society, No. 32, PP 55-63. 